\title{
Predictors of Therapy Efficacy for Homeostatic Post-Stress Disorders
}

\author{
DOI: $10.17691 / \mathrm{stm} 2016.8 .1 .15$
}

Received February 27, 2015

S.A. Mironov, MD, PhD, Associate Professor ${ }^{1}$

S.B. Artifeksov, MD, DSc, Professor ${ }^{2}$

IInstitute of Business, Management and Psychology, 2 Z. Kosmodemyanskoy St., Khimki, Moscow Region, 141400, Russian Federation;

${ }^{2}$ Privolzhsky District Medical Center of Federal Medico-Biologic Agency of Russia,

2 Nizhne-Volzhskaya naberezhnaya St., Nizhny Novgorod, 603005, Russian Federation

The aim of the investigation is to reveal predictors of stress pathogenicity and to study the possibility of their application for monitoring rehabilitation effectiveness in individuals with distress consequences.

Materials and Methods. The study involved 175 males who had suffered once traumatic stress, associated with professional activities. Anamnestic, instrumental and laboratory methods of investigation were used along with psychological techniques and calculation of integral indexes. Besides, to investigate the possibility of applying the predictors for monitoring sanogenetic changes the studied individuals participated in standard rehabilitation programs according to the methods developed by Pogodina et al.

Results. There have been revealed the most informative predictors of stress pathogenicity and therapy efficacy for homeostatic post-stress disorders resulting from interaction of the organism with the environment. It has been established that in individuals with a single exposure to traumatic stress the most informative predictors of stress pathogenicity are vegetative disturbances and sexual status disorders associated with them, such as sexual dysfunctions and family-sexual disharmonies. Complex evaluation of the revealed predictors is possible when applying integral indexes based on measuring vegetative and psychosomatic parameters. It is quite easy to implement and at the same time informative not only for assessment of patients initial condition but also for monitoring rehabilitation effectiveness in individuals with distress consequences.

Key words: predictors of stress pathogenicity; diagnosis of homeostatic disorders; vegetative status; sexual dysfunctions; sanogenetic changes.

Modern economic conditions set specific requirements for medicine: not only complex pathophysiological evaluation of patients and environment is necessary but prominent prognostic orientation of medical and scientific research as well [1].

Developing Pavlov's theory Anokhin came to the conclusion that there exist three levels of automatism maintaining functional condition of homeostatic systems of the organism in general, providing its safety and development as well as working capacity and maximal life duration. The first level, general biological, has been developed in the process of phylogenesis and maintains homeostasis consistancy and life processes. The second one is inherited genetically, it is supported by spinal, brainstem and subcortical segments of central nervous system and determines instinctive behavioral patterns. The third level is the highest, it develops during lifetime of a human being under the influence of his/her personal needs and is connected with the brain cortex [2]. When acquiring an individual experience (such as extreme mental strain associated with actual fear of inevitable death accompanied by utmost uncertainty about the outcome) the information about traumatic stimuli reaching cortical analyzer ends causes significant activity in the prefrontal cortex. When projected to the limbic system this activity leads to corresponding reactivity connected with activation of endocrine and vegetative nuclei in the hypothalamus and the brainstem. Subsequent activation of hypothalamic-pituitary-adrenal and sympathoadrenal systems normally providing adaptation to increased loads, given the extreme mental strain, can be the reason not only for degeneration of noradrenaline axons and death of pyramidal cells in the hippocampus [3, 4], but also for latent acidosis development resulting from ion-radical growth [5].

These data suggests that measuring homeostatic parameters it is possible to make a high probability judgment not only about pathogenicity of stress impact on a certain organism but also about sanogenetic changes in the process of therapy, and their monitoring will allow the evaluation of rehabilitation effectiveness.

The aim of the investigation was to find predictors of stress pathogenicity and to study the possibility of their application for monitoring rehabilitation effectiveness in individuals with distress consequences.

Materials and Methods. The study was performed in one of the health resorts in Russia. The material was obtained as the result of examination of 175 males aged 22 to 64 years (mean age 42 years) carried out in 2010-2012. The patients were divided in two groups.

For contacts: Sergey B. Artifeksov, e-mail: artifex54@mail.ru 
The main group included individuals who were exposed to etiologically homogeneous stress associated with professional activity, experienced as a single-time event of extreme mental strain. This strain was associated with pronounced actual fear of inevitable death accompanied by utmost uncertainty about the outcome and extreme physical exertion (76 persons). The control group comprised individuals who definitely had no such stress in their past history (99 persons).

The patients were divided into age strata as the age difference between them was considerable. The main group was represented by patients of age strata II (26-50 years) and III (51-60 years) -56.6 and $43.4 \%$, respectively. In the control group the patients were included in strata I (20-25 years), II and III - 11.1, 62.6 and $26.3 \%$, respectively.

The study complies with the Declaration of Helsinki (adopted in June 1964 (Helsinki, Finland) and revised in October 2000 (Edinburgh, Scotland)) and was performed following approval by the Ethics Committee of Privolzhsky District Medical Center of Federal MedicoBiologic Agency of Russia. Written informed consent was obtained from every patient.

In order to determine prognostic power of selected integral indexes homeostatic parameters were measured before and after therapeutic intervention in the main group.

The following information was obtained from all the patients under study:

1) case history (a. vitae, a. morbi, family, psychosomatic, traumatic);

2) findings of instrumental and laboratory homeostasis investigations which were used to calculate integral indexes - vegetative index [6], index of functional measurements [7], biological age [8];

3) psychological parameters according to brief scale of post-stress manifestations (BSPSM) [9].

In order to study the possibility of using the selected predictors for monitoring sanogenetic changes the examined individuals additionally participated in standard rehabilitation programs according to the methods developed by Pogodina et al. [10]. All patients from the main group were examined twice, on admission and before discharge.

Statistical data processing was performed by means of the Statistica 6.1 (StatSoft Inc., USA) program. According to distribution type the quantitative data was presented as mean value or median and standard deviation $(\mathrm{M} \pm \mathrm{SD})$, or 25 and $75 \%$ quartiles. For qualitative parameters their relative frequencies were calculated. To test hypotheses for sample differences Mann-Whitney U-test, $\chi^{2}$ criterion, two-tailed Fisher's exact test were used, Spearman rank correlation coefficient was determined as well. The probability of differences between the groups of patients was considered statistically significant at $p \leqslant 0.05$.

Results and Discussion. When evaluating psychological parameters based on BSPSM data analysis no statistically significant differences between the groups were found. However, family history data showed differences between the groups in presenting complaints of "loss of sexual attraction and satisfaction" $(r=0.48 ; p \leqslant 0.05)$, "shyness and tenseness in dealing with persons of the opposite sex" $(r=0.43 ; p \leqslant 0.05)$ and "unnerving sexual thoughts" $(r=0.41 ; p \leqslant 0.05)$. Sexological problems were statistically significantly more frequent in patients of stratum II, the main group: "loss of sexual attraction and satisfaction" - 32.6 [25.4; $39.7] \%$ in the main group compared to $8.1[4.6 ; 11.5] \%$ in the control, "unnerving sexual thoughts" - 14,0 [8.7; $19.2] \%$ in the main group, $4.8[2.1 ; 7.6] \%$ in the control. They felt "shy and tense in dealing with persons of the opposite sex" significantly more seldom (11.6 [6.7; $16.5] \%$ in the main group, $30.7[24.8 ; 36.5] \%$ in the control).

In age stratum III the observed trends were similar to those of the previous one. Individuals from the main group worried about "shyness and tenseness in dealing with persons of the opposite sex" significantly more seldom than the control patients $(24.2[16.8 ; 31.7] \%-$ in the main group and 42.3 [32.6; 52.0$] \%$ in the control). Obviously, these complaints implied development of sexual family disharmonies and dysfunctions, which was confirmed by significant increase in the number of divorces. Thus, the number of divorced patients from the main group was 2.6 times higher $(20.9[14.7 ; 27.1] \%)$ as compared to the control $(8.1[4.6 ; 11.5] \%)$.

The difference between biological and chronological age was calculated in patients of both groups in three age strata - the first integral index for homeostasis evaluation. In this case a negative result suggested that biological age was younger than chronological one and it was considered to be a favorable sign.

There was significant difference between groups in both age strata II $(p \leqslant 0.05)$ and III $(p \leqslant 0.05)$. Maximal favorable difference between these ages was observed in the control patients of age stratum II. In all main group patients of age strata II and III biological age exceeded chronological one, which suggests premature ageing of such patients.

Thus, the analysis of biological age showed that patients, experienced extreme psychological strain, were statistically significantly older compared to those without such experience.

When studying another integral index for homeostasis assessment, vegetative index, it was established that prevailing tone of sympathetic division of the autonomic nervous system (ANS) occurred statistically significantly 2 times as often in the main group patients of stratum II compared to the control $(83.7[78.1 ; 89.4] \%$ vs 41.9 [35.7; 48.2]\%).

The tendency to significant prevailing of sympathicotonia in the main group and stratum III was obvious - it was also 2 times as often compared to the control patients $(54.6[45.9 ; 63.2] \%$ vs 26.9 [18.2; $35.6] \%)$.

Assessment of frequency of psychosomatic and non-psychosomatic diseases showed that there were individuals having several disorders at the same time in 
stratum II among 62 patients of the control group and 43 patients of the main group. And there were statistically significantly (2.5 times) more patients with hypertensive disease among such individuals in the main group (65.1 [57.9; 72.4]\% vs $25.8[20.3 ; 31.4] \%$ in the control), and 2.1 times more patients with peptic ulcer disease (46.5 [38.9; 54.1$] \%$ vs $22.6[17.3 ; 27.9] \%$ in the control). Diabetes mellitus type 2, arrhythmia and impaired conductivity occurred equally seldom in both groups.

Most of 26 control patients from age stratum III and 33 main group patients of the same age had several disorders at the same time. In the main group patients with hypertensive disease were statistically significantly (2.1 times) more numerous (72.7 [65.0; 80.5]\% vs 34.6 [25.3; 44.0]\% in the control), patients with peptic ulcer disease -2.3 times $(69.7[61.7 ; 77.7] \%$ vs 30.8 [21.7; $39.8] \%$ in the control).

We also analyzed index of functional measurements as a possible pathogenicity predictor, an indicator integrally reflecting functional state of the organism ANS and involving pulse rate, arterial blood pressure, age, physical state, including body weight and height. Being an integral index of vegetative homeostasis it provides the possibility to evaluate functional resources and make health prognosis.

In the main group $46.5[38.9 ; 54.1] \%$ of patients were found to have reduced functional capacities of ANS, requiring more detailed examination and secondary preventive care with participation of a doctor.

Among the main group patients of age stratum III the majority of individuals had reduced functional capacities of ANS - 63.6 [55.3; 72.0]\%, which 3.3 times exceeded the number of such patients in the control group -19.2 $[11.5 ; 27.0] \%$.

Since the aim of our investigation was to find the most informative predictors of stress pathogenicity and to study the possibility of their application for monitoring rehabilitation effectiveness in individuals with distress consequences, the patients were repeatedly examined after the standard rehabilitation course [10]. The results were compared to those obtained on admission. The integral indexes were also proved by the analysis to be informative as predictors taking into consideration fundamental sanogenesis components in therapy efficacy evaluation because the reduced tone of sympathetic nervous system was observed in the majority of cases. The number of patients with parasympathotonia from stratum II of the main group increased statistically significantly (10 times) after the performed correction $(4.7[1.4 ; 7.9] \%$ before and 46.5 $[38.9 ; 54.1] \%$ after rehabilitation). Similarly to stratum II, though to a less extent, patients from stratum III of the main group were found to have statistically significant decrease in the sympathetic effect and increase in the parasympathetic one. Integral indexes revealed statistically significant increase in functional capacities of ANS on completing rehabilitation in $46.5[38.9 ; 54.1] \%$ of the main group patients from age stratum II $(p=0.0001)$ and in $39.4[30.9 ; 47.9] \%$ of patients from stratum III. Consistently, more prominent improvement of functional capacities and adaptiveness was observed in stratum II compared to the patients from stratum III.

Besides, on completing a standard rehabilitation course statistically significant normalization of psychological parameters was observed, which was proved by the results of repeated evaluation of BSPSM indexes: improvement amounted to $13.1 \%(2.2[1.2 ; 3.1] \%$ on admission and $0.8[0.6 ; 1.1] \%$ after rehabilitation). It should be noted that improvement of psychological parameters as well as statistically significant positive dynamics of the above-described sexological status parameters revealed in our study were consistently observed only concurrently with normalization of integral indexes of vegetative status evaluation.

Conclusion. The most informative predictors of stress pathogenicity in individuals with a single-time traumatic stress experience are vegetative disturbances and associated sexual status disorders, such as sexual dysfunctions and family-sexual disharmonies. Complex evaluation of the revealed predictors with application of integral indexes, based on measuring vegetative and psychosomatic parameters (vegetative index, index of functional measurement and biological age), is quite easily implemented and, at the same, time is informative not only for assessment of patients' initial condition but also for monitoring rehabilitation effectiveness in individuals with distress consequences.

Study Funding and Conflicts Interest. This study was not supported by any financial sources and there is no topic specific conflicts of interest related to the authors of this study.

\section{References}

1. Aleksandrovich Yu.S., Gordeev V.I. Otsenochnye $i$ prognosticheskie shkaly $v$ meditsine kriticheskikh sostoyaniy [Evaluative and prognostic scales in critical care medicine]. Saint Petersburg: ELBI-SPb; 2010; 248 p.

2. Bodrov V.A. "Coping stress" problem. Part I: "Coping stress" and theoretical approaches to its study. Psikhologicheskiy zhurnal 2006; 27(1): 122-133.

3. Asberg M., Nygren A., Leopardi R., Rylander G., Peterson U., Wilczek L., Kéllmän H., Ekstedt M., Akerstedt T., Lekander M., Ekman R. Novel biochemical markers of psychosocial stress in women. PLoS One 2009; 4(1): e3590, http://dx.doi.org/10.1371/journal.pone.0003590.

4. Baune B. Conceptual challenges of a tentative model of stress-induced depression. PLoS One 2009; 4(1): e4266, http:// dx.doi.org/10.1371/journal.pone.0004266.

5. Nutt D.J. Neurobiological mechanisms in generalized anxiety disorder. J Clin Psychiatry 2001; 62(Suppl 11): 22-27.

6. Podushkina I.V., Dobrzhanskiy V.V., Kuznetsov A.A., Dmitrochenkov A.V. Kriterii $i$ metody otsenki sostoyaniya zdorov'ya [Methods and criteria for health assessment]. Nizhny Novgorod; 2007.

7. Pushkova E.S., Ksenz N.V. Organization of work in premature senility aging prevention group. Klinicheskaya gerontologiya 2000; 9: 63-67.

8. Semke V.Ya., Epanchintseva E.M. Typology and clinical dynamics of post-traumatic stress disorder in combatants. Rossiyskiy psikhiatricheskiy zhurnal 2001; 5: 19-23. 
9. Kotenev I.O. Psikhologicheskaya diagnostika poststressovykh sostoyaniy u sotrudnikov organov vnutrennikh del [Psychological diagnosis of post-stress status in law enforcement officials]. Moscow; 1997.
10. Pogodina T.G., Zuykova A.A., Balchugov V.A. Osnovy mediko-psikhologicheskoy reabilitatsii lits opasnykh professiy [Fundamentals of medical and psychological adjustment of individuals with hazardous occupations]. Nizhny Novgorod; 2007. 